\title{
AnÁlise do Crescimento de Hyptis suaveolens ${ }^{1}$
}

\author{
Growth Analysis of Hyptis suaveolens
}

\author{
GRAVENA R. ${ }^{2}$, PEDRINHO JÚNIOR, A.F.F. ${ }^{3}$, BARBOSA JÚNIOR, A.F. ${ }^{4}$, BIANCO, S. ${ }^{5}$ e \\ PITELLI, R.A. ${ }^{5}$
}

\begin{abstract}
RESUMO - O crescimento de $H$. suaveolens foi estudado em casa de vegetação, no delineamento experimental inteiramente casualizado, com quatro repetições. As plantas cresceram em vasos com capacidade de cinco litros, preenchidos com areia e irrigados com solução nutritiva, diariamente. Os atributos de crescimento das plantas foram avaliados dos 20 até os 160 dias após a emergência (DAE) da planta daninha, em intervalos regulares de 14 dias. A planta atingiu o máximo estimado de biomassa seca acumulada aos 145 DAE. A partir da emergência, até 104 dias, as folhas apresentaram maior participação no acúmulo de biomassa seca total da planta; posteriormente, os caules passaram a deter maior proporção dessa característica. A taxa de assimilação líquida foi crescente do início do ciclo até a época estimada de 71 DAE, decrescendo a seguir, provavelmente devido ao auto-sombreamento das folhas. A análise do crescimento indicou que $H$. suaveolens pode apresentar alta capacidade competitiva, podendo ser considerada planta infestante de crescimento tardio, quando presente nas culturas anuais de verão.
\end{abstract}

Palavras-chave: taxa de crescimento, planta daninha, Glycine max.

\begin{abstract}
The growth of $\boldsymbol{H}$. suaveolens was evaluated in greenhouse conditions, using a randomized design, with four replications. The plants were grown in 5-liter pots filled with sand and irrigated daily with a nutritive solution. The growth atributes were evaluated from 20 to 160 days after weed emergence (DAE), at 14-day regular intervals. The maximum estimated dry biomass accumulation of the plant occurred at 145 DAE. Until 104 DAE, the greatest amount of dry matter was partitioned to the leaves. After 104 DAE, most of the dry matter was partitioned to the stems. The net assimilation rate (NAR) increased from the beginning of the weed cycle to 71 DAE. After this period, the NAR decreased, probably due to the self-shading of the leaves. Growth analysis indicated that $\boldsymbol{H}$. suaveolens could be highly competitive, and based on its growth habit, it can be considered a late growth weed in the annual summer crop cycle.
\end{abstract}

Key words: growth rate, weed, Glycine max.

\section{INTRODUÇÃO}

A interferência das plantas daninhas nos cultivos agrícolas é influenciada por diversos fatores, relacionados à própria comunidade infestante, à cultura e às condições ambientais de desenvolvimento da cultura e das plantas infestantes (Pitelli, 1985). A composição específica da comunidade infestante é um fator de fundamental importância na determinação do grau de interferência, pois as espécies de plantas integrantes da comunidade variam

Recebido para publicação em 20/11/2001 e na forma revisada em 7/8/2002.

2 Eng.-Agr., aluno de doutorado do curso de Fitotecnia da ESALQ/USP, Av. Pádua Dias, 11, 13418-900 Piracicaba-SP, Brasil. ${ }^{3}$ Eng.-Agr., aluno de mestrado do curso de Produção Vegetal da FCAV/UNESP, Jaboticabal-SP, Brasil. ${ }^{4}$ Eng.-Agr. ${ }^{5}$ Prof. Dr., Dep. de Biologia Aplicada à Agropecuária da FCAV/UNESP, Via de Acesso Prof. Paulo Donato Castellane, s/n, 14887-014 Jaboticabal-SP, Brasil. 
bastante em relação aos seus hábitos de crescimento e exigências em recursos do meio. Normalmente, as plantas que apresentam maior porte e crescimento mais rápido são as que causam maior interferência competitiva (Roush \& Radosevich, 1985).

Os estudos de crescimento de plantas têm sido freqüentemente utilizados para o conhecimento da ecologia de diferentes espécies e para análises comparativas entre plantas daninhas e culturas (Felício, 1979; Radosevich \& Holt, 1984; Patterson, 1985; Rejmanek et al., 1989; Dunan \& Zimdahl, 1991; Christoffoleti et al., 1997; Erasmo et al., 1997; Tanji et al., 1997; Silva \& Marenco, 2000; Brighenti et al., 2001; Christoffoleti, 2001). Quanto à importância desses estudos no conhecimento da ecologia das plantas daninhas, Roush \& Radosevich (1985) constataram que as taxas de crescimento podem refletir a habilidade e a hierarquia competitiva das espécies na comunidade vegetal e Grime \& Hunt (1975) verificaram que a magnitude da taxa de crescimento relativo (TCR) pode refletir o tipo de ambiente de origem das plantas daninhas.

Hyptis suaveolens é uma planta daninha da familia Labiatae, subarbustiva, que apresenta ampla distribuição geográfica no território brasileiro, ocorrendo com maior freqüência nas regiões de cerrado, em áreas de cultivo de soja, onde pode atingir altas densidades populacionais (Barros et al., 1987; Lorenzi, 1991). Além de ser encontrada no Brasil, essa planta também é citada em outros países, como a Austrália, onde é considerada uma importante planta invasora, sendo alvo de programas de controle biológico (Buzzi \& Winder, 1986).

O presente trabalho teve como objetivo estudar as principais características do crescimento de $H$. suaveolens, levando em consideração a importância que apresentam esses estudos para o conhecimento da ecologia dessa espécie e dos processos de interferência estabelecidos com as culturas.

\section{MATERIAL E MÉTODOS}

O experimento foi conduzido em casa de vegetação, na área experimental do Departamento de Biologia Aplicada à Agropecuária da FCAV/UNESP, campus de Jaboticabal, nos meses de setembro de 1999 a fevereiro de 2000.
Os recipientes utilizados no crescimento das plantas de Hyptis suaveolens foram vasos plásticos com capacidade para cinco litros, com fundos perfurados e conectados a mangueiras de plástico de $1,0 \mathrm{~cm}$ de diâmetro e $75,0 \mathrm{~cm}$ de comprimento. As extremidades posteriores das mangueiras foram conectadas a frascos de vidro com capacidade de um litro. Esse sistema teve a finalidade de coletar os excessos de solução lixiviada nas irrigações, para posteriores reposições nas irrigações seguintes. O substrato utilizado para o crescimento das plantas foi areia de rio lavada e peneirada em peneira de malha de $5 \mathrm{~mm}$. A semeadura foi realizada a $1 \mathrm{~cm}$ de profundidade, depositando-se $50 \mathrm{se}-$ mentes por vaso. Quando as plântulas atingiram o estádio de dois pares de folhas verdadeiras, totalmente expandidas, efetuou-se o desbaste, deixando-se quatro plantas por vaso.

Os vasos foram irrigados com solução nutritiva completa de Hoagland \& Arnon (1950), recebendo $25 \%$ da concentração original durante os primeiros 21 dias após a semeadura e, posteriormente, $50 \%$ até o final da fase experimental, seguindo o procedimento adotado por Fernandes (1997). As irrigações foram realizadas com volume de solução suficiente para iniciar a percolação para os vidros coletores. Efetuou-se uma irrigação por dia, até 60 dias após a semeadura. No período subseqüente, até o final da fase experimental, foram realizadas duas irrigações diárias, em função do aumento na demanda evapotranspiratória.

Os tratamentos foram constituídos por épocas de coletas das plantas, realizadas em intervalos regulares, aos $20,34,48,62,76$, $90,104,118,132,146$ e 160 dias após a emergência das plantas. $O$ delineamento experimental foi o inteiramente casualizado, com 11 tratamentos e quatro repetições, sendo os vasos distribuídos aleatoriamente na casa de vegetação e suas posições alternadas semanalmente.

As avaliações foram realizadas separandose as diferentes partes das plantas, que, em seguida, foram lavadas na seqüência proposta por Sarruge \& Haag (1974), com rápida imersão em solução diluída de detergente neutro, lavagem por imersão em água destilada e imersão em água deionizada. Antes da lavagem, foram separadas, aleatoriamente, 20 folhas de cada planta, cujas áreas foliares foram determinadas pelo medidor de área $\mathrm{Li}$-cor Instruments, 
modelo LI-3000A. Após a lavagem, as diferentes partes das plantas foram secas em estufa de renovação forçada de ar a $60-70{ }^{\circ} \mathrm{C}$, até peso constante.

As áreas foliares totais das plantas foram estimadas por meio de regra de três simples, relacionando a biomassa seca e a área foliar das 20 folhas com a biomassa seca total das folhas. Com base nos resultados de biomassa seca acumulada e área foliar, foram determinadas, para cada avaliação, a taxa de crescimento absoluto (TCA), a taxa de crescimento relativo (TCR), a taxa de assimilação líquida (TAL), a razão de área foliar (RAF) e a razão de peso foliar (RPF), segundo fórmulas sugeridas por Benincasa (1988).

A TCA representa a biomassa seca acumulada por intervalo de tempo, sendo calculada pela fórmula TCA $=\left(\mathrm{P}_{n}-\mathrm{P}_{n-1}\right) /\left(\mathrm{T}_{\mathrm{n}}-\mathrm{T}_{\mathrm{n}-1}\right)$, em que $\mathrm{P}_{\mathrm{n}}$ é a biomassa seca acumulada até a avaliação $\mathrm{n}, \mathrm{P}_{\mathrm{n}-1}$ é a biomassa seca acumulada até a avaliação $\mathrm{n}-1, \mathrm{~T}_{\mathrm{n}}$ é o número de dias após a emergência, por ocasião da avaliação $n$, e $T_{n-1}$ é o número de dias após a emergência, por ocasião da avaliação n-1. A TCR expressa o crescimento da planta em um intervalo de tempo, em relação à biomassa seca acumulada no início desse intervalo, sendo calculada pela fórmula $T C R=\left(\ln P_{n}-\ln P_{n-1}\right) /\left(T_{n}-T_{n-1}\right)$. A TAL representa $a$ taxa de fotossíntese líquida e é determinada pela relação entre as biomassas secas produzidas por área foliar da planta, por um determinado intervalo de tempo, sendo calculada pela fórmula $T A L=\left[\left(P_{n}-P_{n-1}\right) /\left(T_{n}-T_{n-1}\right)\right] \cdot\left[\left(\ln A_{n}-\ln A_{n-1}\right) /\right.$ $\left.\left(A_{n}-A_{n-1}\right)\right]$, em que $A_{n}$ é a área foliar da planta, por ocasião da avaliação $n, \mathrm{e}_{\mathrm{n}-1}$ é a área foliar da planta, por ocasião da avaliação n-1. A RAF representa a relação entre a área responsável pela realização da fotossíntese e a biomassa seca total produzida, sendo calculada pela fórmula $\mathrm{RAF}=\mathrm{A}_{\mathrm{n}} / \mathrm{P}_{\mathrm{n}}$. A RPF representa a relação entre a biomassa seca das folhas e a biomassa seca total da planta, sendo calculada pela fórmula $\mathrm{RPF}=\mathrm{Pf}_{\mathrm{n}} / \mathrm{P}_{\mathrm{n}}$, em que $\mathrm{Pf}_{\mathrm{n}}$ é a biomassa seca das folhas, por ocasião da avaliação $n$.

Os dados obtidos foram submetidos à análise de regressão pela equação exponencial $y=\exp \left(a+b x+c x^{2}\right)$, sendo y a variável dependente em estudo e $\mathrm{x}$ a variável independente (tempo). Para a escolha da equação de regressão foram considerados a lógica do fenômeno biológico e o valor do coeficiente de determinação. As estimativas dos pontos de inflexão e de máxima da curva foram determinadas pela derivada primeira e segunda da equação ajustada aos dados obtidos.

\section{RESULTADOS E DISCUSSÃO}

As plantas de Hyptis suaveolens iniciaram o período reprodutivo entre 104 e 118 dias após a emergência (DAE), com o aparecimento de algumas flores. A maioria das flores não produziu frutos. Dessa forma, devido ao reduzido acúmulo de biomassa seca nas partes reprodutivas das plantas, não foi de interesse prático a separação das inflorescências e infrutescências dos caules. Portanto, as diferentes partes de $H$. suaveolens estão representadas apenas por raízes, caules e folhas.

Guanto ao acúmulo de biomassa seca, todas as partes de $H$. suaveolens apresentaram comportamento semelhante ao longo do ciclo de desenvolvimento (Figura 1). A espécie apresentou acúmulo de biomassa seca total crescente até a época estimada de $145 \mathrm{DAE}$, quando, em seguida, se iniciou o processo de senescência. Portanto, o ciclo total de crescimento de $H$. suaveolens foi de 145 dias.

O ponto de inflexão para o acúmulo de biomassa seca da planta ocorreu aos $118 \mathrm{DAE}$, correspondendo à época na qual a taxa de crescimento absoluto (TCA) é máxima. Essa taxa é um indicativo da velocidade de crescimento e seu valor médio foi de $0,96 \mathrm{~g} \mathrm{dia}^{-1}$, quando considerados somente os valores positivos, ou seja, valores obtidos antes do início da senescência da planta.

O acúmulo máximo de biomassa seca total foi de $112 \mathrm{~g} \mathrm{planta}^{-1}$, valor superior ao obtido por outras plantas daninhas da cultura da soja que freqüentemente são encontradas nas regiões de cerrado, como Senna obtusifolia (Erasmo et al., 1997), Commelina benghalensis (Rodrigues, 1992) e Acanthospermum hispidum (Andreani Jr., 1995), quando considerado o período em que estas podem conviver com as culturas anuais (0-148 DAE).

No período inicial do ciclo, em comparação com outras plantas daninhas, $H$. suaveolens apresentou lento crescimento, acumulando, ao final de 104 DAE, o valor estimado de apenas 


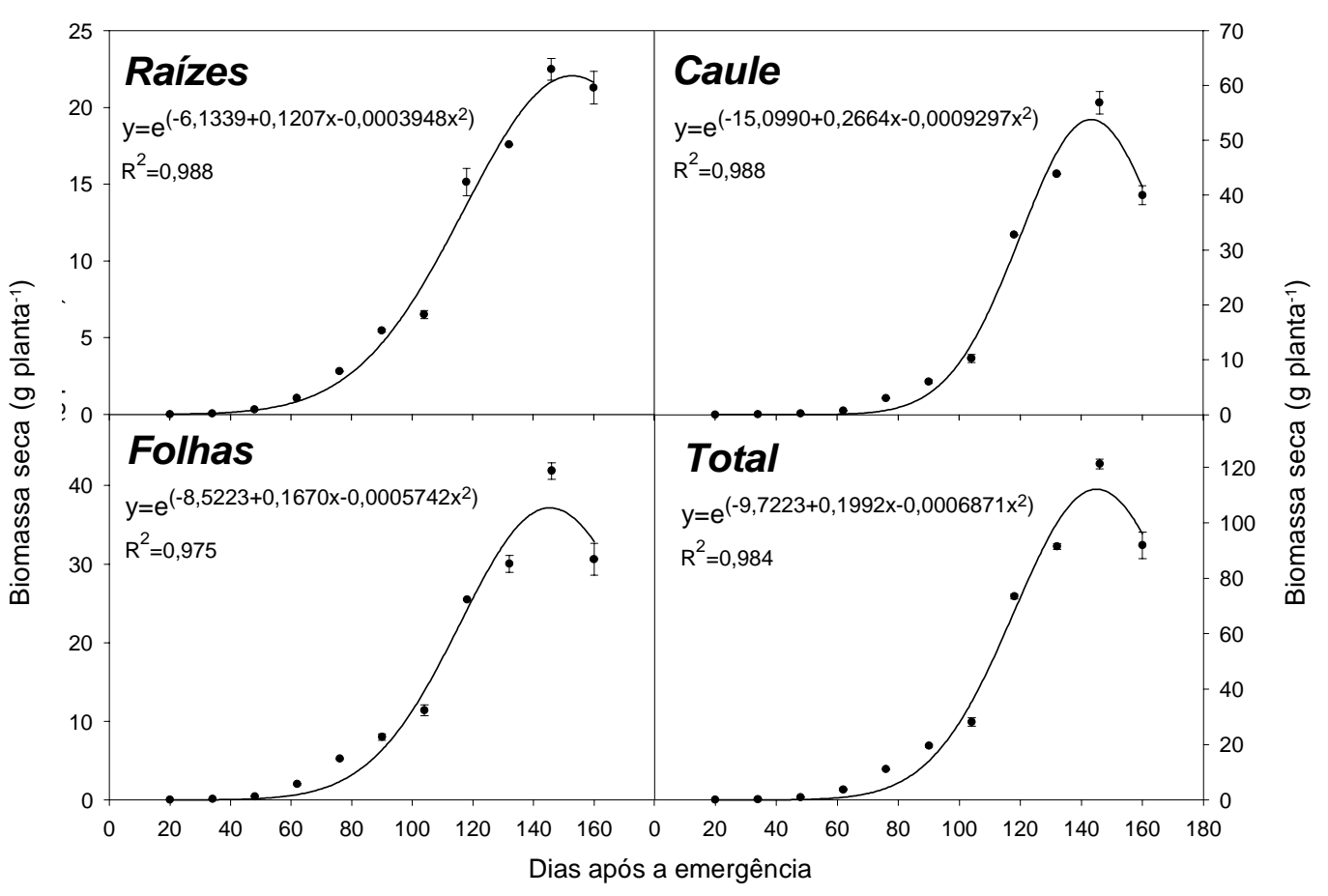

Figura 1 - Acúmulo de biomassa seca nas diferentes partes da planta de Hyptis suaveolens ao longo do seu ciclo de desenvolvimento.

$35 \mathrm{~g}$ planta $^{-1}$, que representa $31 \%$ da biomassa seca total acumulada. S. obtusifolia, aos 91 DAE, acumulou 39,91 g planta $^{-1}$, representando 50\% do total obtido pela planta (Erasmo, 1995), e C. benghalensis, aos 98 DAE, acumulou 47,6 g planta $^{-1}$, correspondendo a $52 \%$ do total acumulado no período em que a planta pode conviver com as culturas anuais, aproximadamente entre zero e 148 DAE (Rodrigues, 1992).

Considerando a distribuição percentual da biomassa seca da planta daninha ao longo do ciclo de crescimento, durante os primeiros 104 dias, as folhas apresentaram maiores acúmulos de biomassa seca em relação às demais partes das plantas, sendo responsável por valores entre 40 e $54 \%$ do total da planta (Figura 2). Nesse mesmo período, os caules apresentaram acúmulos entre 19 e 36\%. Após o período inicial de 104 dias ocorreu inversão na representatividade das folhas e dos caules. $O$ valor percentual das folhas passou a ser menor, representando entre 33 e 35\% do total acumulado. Os caules passaram a representar entre 45 e $48 \%$. O percentual das raízes foi menos variável durante todo o ciclo da planta daninha, apresentando valores entre 19 e 33\%, provavelmente devido ao efeito limitante do volume do vaso (Figura 2). Portanto, com o aumento do porte da planta houve maior participação dos caules na biomassa seca acumulada. Essa inversão na representatividade de caules e folhas também foi constatada para S. obtusifolia (Erasmo et al., 1997), A. hispidum (Andreani Jr., 1995), C. benghalensis (Rodrigues, 1992), Cenchrus echinatus (Pavani, 1992), Amaranthus retroflexus (Fernandes, 1997) e Sida rhombifolia (Deangelo, 1995).

Todas as partes de Hyptis suaveolens apresentaram comportamento semelhante quanto às taxas de crescimento relativo (TCR) obtidas ao longo do ciclo de desenvolvimento (Figura 3). Os valores para TCR foram decrescentes com o tempo. Até $76 \mathrm{DAE}$ os caules apresentaram menor redução na TCR, em relação às demais partes, resultando em maior TCR média $\left(0,68 \mathrm{~g} \mathrm{~g}^{-1} \mathrm{dia}^{-1}\right.$ contra 0,61 das raízes e 0,60 das folhas, considerando somente as taxas positivas de crescimento relativo). Esse comportamento explica o aumento da representatividade dos caules no percentual de biomassa seca acumulada durante o ciclo (Figura 2). 


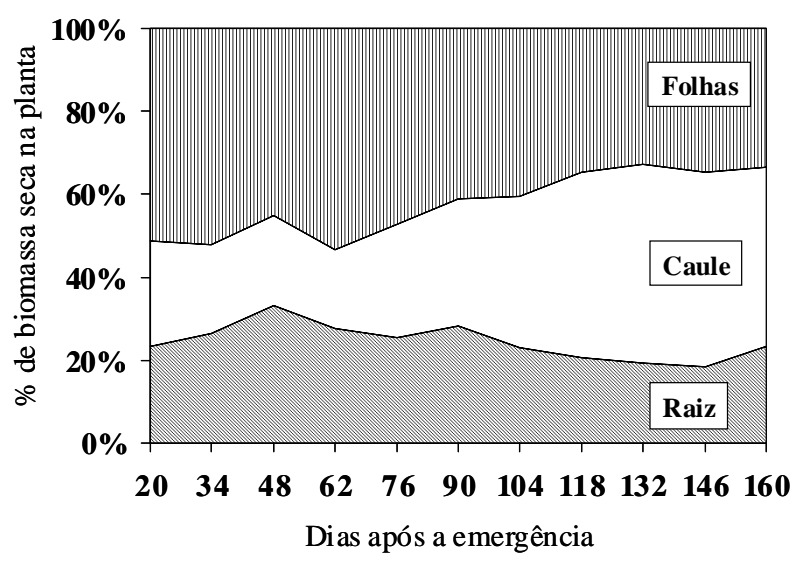

Figura 2 - Distribuição percentual de biomassa seca nas diferentes partes da planta de Hyptis suaveolens ao longo do ciclo de desenvolvimento.

Com o aumento da biomassa seca acumulada pelas plantas, ocorre aumento na necessidade de fotossintatos para a manutenção das estruturas já formadas; assim, a quantidade de fotossintatos disponível para o crescimento tende a ser menor e conseqüentemente a TCR é decrescente com o tempo (Benincasa, 1988).
Tendências semelhantes também já foram observadas em outras plantas daninhas e plantas cultivadas (Hunt \& Bazzaz, 1980; Velini, 1989; Pavani, 1992; Rodrigues, 1992; Andreani Jr., 1995; Deangelo, 1995; Erasmo et al., 1997; Fernandes, 1997). Levando-se em conta as taxas positivas de crescimento relativo, o valor médio para o total de biomassa seca acumulada por Hyptis suaveolens foi de $0,063 \mathrm{~g} \mathrm{~g}^{-1} \mathrm{dia}^{-1}$. Esse valor foi inferior ao obtido por Erasmo et al. (1997) para Senna obtusifolia $\left(0,091 \mathrm{~g} \mathrm{~g}^{-1} \mathrm{dia}^{-1}\right)$ e superior aos obtido por Rodrigues (1992) e Andreani Jr. (1995) para Commelina benghalensis $\left(0,061 \mathrm{~g} \mathrm{~g}^{-1} \mathrm{dia}^{-1}\right)$ e para Acanthospermum hispidum $\left(0,059 \mathrm{~g} \mathrm{~g}^{-1} \mathrm{dia}^{-1}\right)$, respectivamente.

A área foliar de $H$. suaveolens foi crescente até 146 dias após o plantio (Figura 4), quando em seguida se iniciou o processo de senescência, ocorrendo perdas de folhas e, conseqüentemente, redução na área foliar. O aumento na área foliar da planta foi semelhante ao aumento na biomassa seca acumulada, com o ponto de inflexão da curva ocorrendo aos 122 DAE.

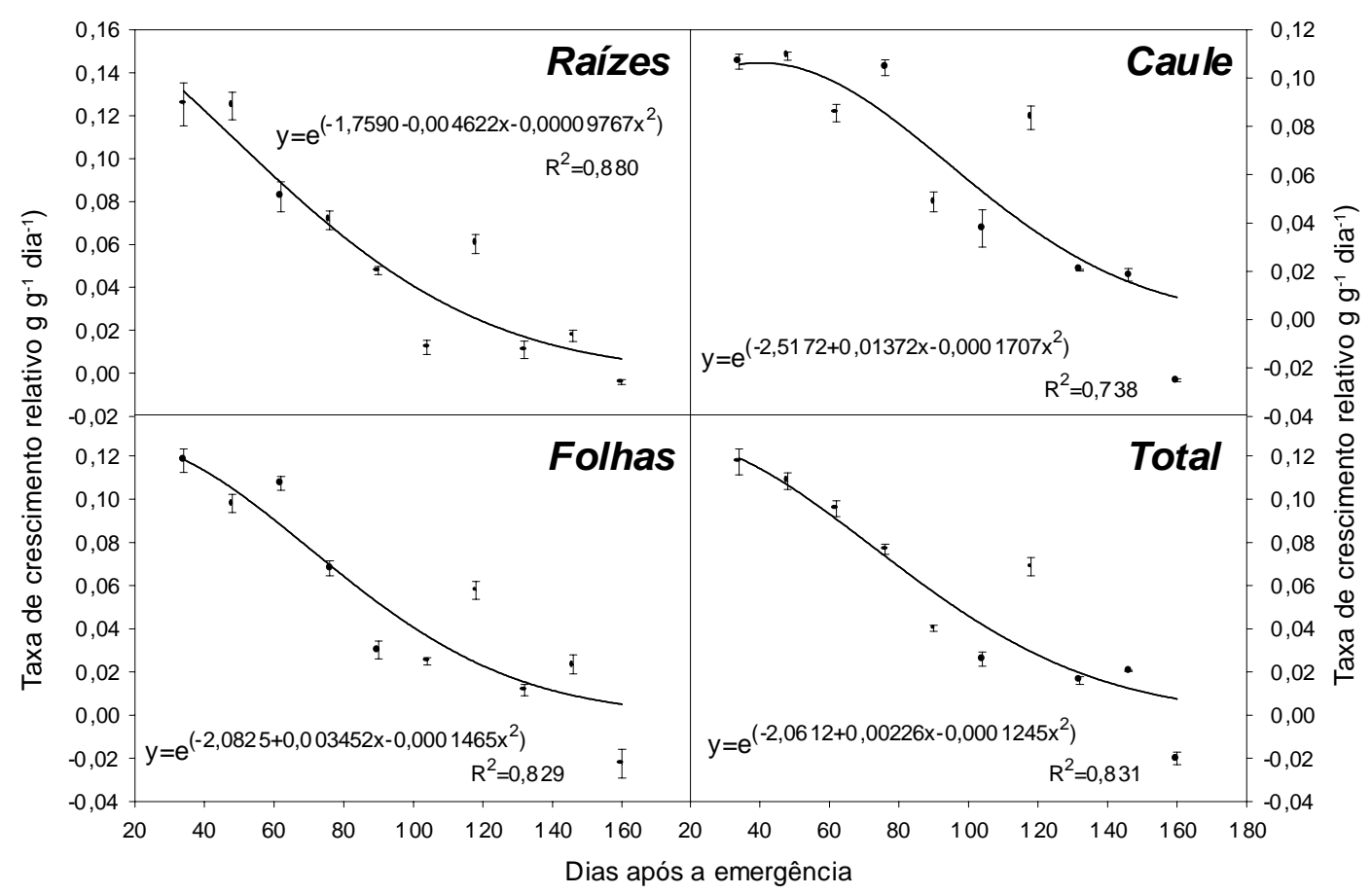

Figura 3 - Taxas de crescimento relativo (TCR) das diferentes partes das plantas de Hyptis suaveolens ao longo do ciclo de crescimento. 


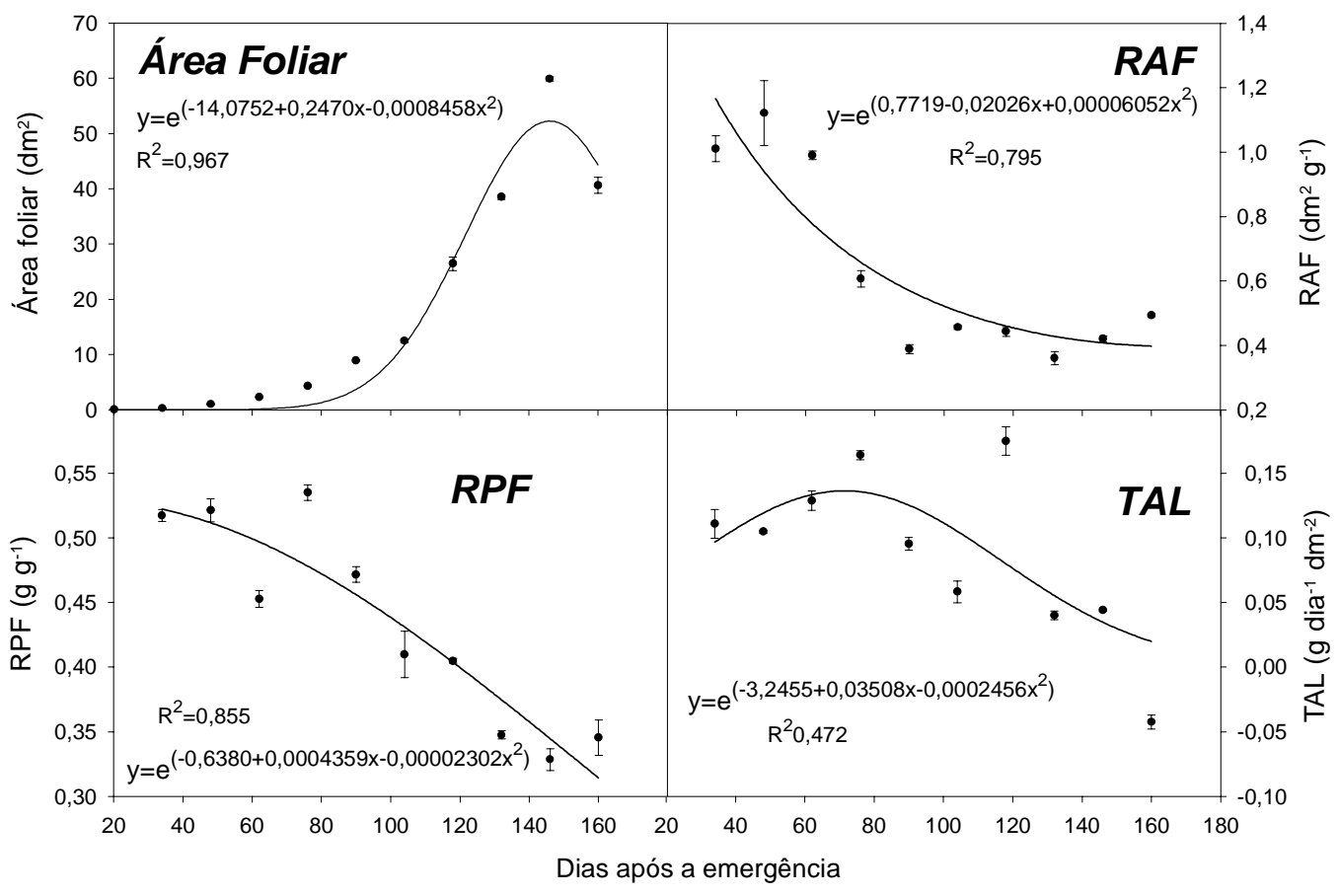

Figura 4 - Área foliar, razão da área foliar (RAF), razão do peso foliar (RPF) e taxa de assimilação líquida (TAL) de Hyptis suaveolens ao longo do ciclo de crescimento.

A razão de área foliar (RAF), que é um indice morfológico de crescimento que representa a área foliar útil para realizar esse processo, e a razão de peso de folha (RPF), que reflete a proporção entre o material produzido pela folha que não foi exportado para o resto da planta e o total de biomassa seca acumulado pela planta (Benincasa, 1988), foram decrescentes durante o crescimento da planta. Esses resultados mostraram-se semelhantes aos obtidos para outras plantas daninhas e culturas (Pavani, 1992; Fernandes, 1997; Deangelo, 1995; Felício, 1979; Rodrigues, 1992; Erasmo et al., 1997). A RAF apresentou rápida queda no início do ciclo, tendendo à constância no final. Já a RPF apresentou menor decréscimo inicial, tendendo a um decréscimo linear ao final do ciclo. Dessa forma, os resultados obtidos indicam que, com o crescimento da planta, ocorreu menor área fotossintética útil e menor participação das folhas na biomassa seca acumulada. Considerando-se somente as taxas positivas, os valores médios obtidos para a RAF e a RPF foram de $0,64 \mathrm{dm}^{2} \mathrm{~g}^{-1}$ e $0,44 \mathrm{~g} \mathrm{~g}^{-1}$, respectivamente.

A taxa de assimilação líquida (TAL) tendeu a ser crescente até 71 dias após a emergência, indicando alta capacidade fotossintética da planta nos estádios iniciais de desenvolvimento. Posteriormente ocorreu o decréscimo, provavelmente devido ao auto-sombreamento das folhas (Erasmo et al., 1997). A TAL média foi de $0,102 \mathrm{~g} \mathrm{dm}^{-2} \mathrm{dia}^{-1}$, considerando-se somente as taxas positivas.

Assim como a biomassa seca acumulada pela planta, a RAF e a TAL podem ser correlacionadas com a capacidade competitiva das plantas daninhas (Roush \& Radosevich, 1985). Para a RAF, quanto maior o seu valor, menor é a competitividade da espécie, ao passo que para a TAL o comportamento é oposto. Dessa forma, comparando os resultados obtidos para H. suaveolens com os obtidos para S. obtusifolia (Erasmo et al., 1997) e C. benghalensis (Rodrigues, 1992), em condições metodológicas similares, $H$. suaveolens pode possuir maior capacidade competitiva durante o período em que as plantas daninhas podem conviver com as culturas anuais, pois apresenta maior biomassa seca acumulada e, também, menores valores para RAF e maiores para TAL. Entretanto, é importante destacar que, em diferentes condições de desenvolvimento, ou em condições 
naturais, outros atributos das plantas e a interação entre fatores ecológicos (bióticos ou abióticos) podem influenciar a capacidade competitiva das espécies (Roush \& Radosevich, 1985).

Um atributo que pode ser prejudicial às plantas de Hyptis suaveolens, na competição com outras plantas daninhas, é o lento crescimento inicial. Dessa forma, no início do desenvolvimento, as plantas de $H$. suaveolens podem ser suprimidas pelo desenvolvimento mais rápido de outras espécies da comunidade infestante. Considerando o crescimento inicial lento e o grande acúmulo de biomassa seca, na fase final de seu ciclo, $H$. suaveolens, em relação a outras espécies de plantas daninhas, pode ser considerada uma planta de crescimento tardio no ciclo das culturas anuais de verão.

\section{LITERATURA CITADA}

ANDREANI Jr., R. Estudos sobre a dormência das sementes, o crescimento e a absorção de macronutrientes por plantas de Acanthospermum hispidum DC. Jaboticabal: FCAV/UNESP, 1995. 72 p. Dissertação (Mestrado em Produção Vegetal) - Universidade Estadual Paulista, 1995.

BARROS, A. C.; EICHLER, V.; BARROS, A. C. Controle de plantas daninhas na cultura da soja através de redução de espaçamentos e da aplicação de herbicidas pós-emergentes. Jataí: EMBRAPA, 1987. 7 p. (Comunicado técnico, 12)

BENINCASA, M. M. P. Análise de crescimento de plantas (Noções Básicas). Jaboticabal: FUNEP, 1988. 42 p.

BRIGHENTI, A. M. et al. Análise de crescimento de bótipos de amendoim-bravo (Euphorbia heterophylla) resistente e susceptível aos herbicidas inibidores de ALS. Planta Daninha, v. 19, n. 1, p. 51-60, 2001.

BUZZI, Z. J.; WINDER J. A. Stages and life cycle of Drepanocassis profana (Boh., 1855) (Coleoptera, Chrysomelidae, Cassidinae) from Hyptis suaveolens (L.) Poit. (Labiatae) in Brazil. R. Bras. Entomol., v. 30, n. 1, p. 31-41, 1986.

CHRISTOFFOLETI, P. J.; WESTRA, P.; MOORE III, F. Growth analysis of sulfonylurea-resistant and susceptible kochia (Kochia scoparia). Weed Sci., v. 45, p. 691-695, 1997.

CHRISTOFFOLETI, P. J. Análise comparativa do crescimento de bótipos de picão-preto (Bidens pilosa) resistente e susceptível aos herbicidas inibidores de ALS. Planta Daninha, v. 19, n. 1, p. 75-84, 2001.
DEANGELO, R. Crescimento e nutrição mineral de Sida rhombifolia L.. Jaboticabal: FCAV/UNESP, 1995. 77 p. Monografia (Graduação em Agronomia) - Universidade Estadual Paulista, 1995.

DUNAN, C.; ZIMDAHL, R. L. Competitive ability of wild oats (Avena fatua) and spring barley (Hordeum vulgare).

Weed Sci., v. 39, p. 558-563, 1991.

ERASMO, E. A. L. Crescimento, nutrição mineral e resposta à calagem em Senna obtusifolia (L.) Irwin \& Barneby. Jaboticabal: FCAV/UNESP, 1995. 88 p. Tese (Doutorado em Produção Vegetal) - Universidade Estadual Paulista, 1995.

ERASMO, E. A. L.; BIANCO S.; PITELLI R. A. Estudo sobre o crescimento de fedegoso. Planta Daninha, v. 15, n. 2, p. 170-179, 1997.

FELÍCIO, M. A. Produção de matéria seca e crescimento da área foliar em cinco cultivares de Zea mays $\mathrm{L}$. Jaboticabal: FCAV/UNESP, 1979. 66 p. Monografia (Graduação em Agronomia) - Universidade Estadual Paulista, 1979.

FERNANDES, G. F. Crescimento e nutrição mineral de Amaranthus retroflexus L.. Jaboticabal: FCAV/UNESP, 1997. 72 p. Monografia (Graduação em Agronomia) Universidade Estadual Paulista, 1997.

GRIME, J. P.; HUNT, R. Relative growth-rate: its range and adaptive significance in a local flora. Ecology, v. 63, n. 2, p. 393-422, 1975.

HOAGLAND, D. R.; ARNON, D. J. The water culture method of growing plants without soil. Berkeley: University of California, 1950.

HUNT, R.; BAZZAZ, F. A. The biology of Ambrosia trifida L. V. Response to fertilizer, with growth analysis at the organismal and sub-organismal levels. New Phytol., v. 84, p. 113-121, 1980.

LORENZI, H. Plantas daninhas do Brasil. 2.ed. Nova Odessa: Plantarum, 1991. 440 p.

PATTERSON, D. T. Comparative ecophysiology of weeds and crops. In: DUKE S. O. (Ed.) Reproduction and ecophysiology. Weed physiology. Boca Raton: CCR Press, 1985. p. 101-129.

PAVANI, M. C. M. D. Estudos sobre o crescimento, nutrição mineral de Cenchrus echinatus $\mathrm{L}$. e resposta a diferentes níveis de fósforo, pH e calagem. Jaboticabal: FCAV/UNESP, 1992. 110 p. Tese (Doutorado em Produção Vegetal) -Universidade Estadual Paulista, 1992.

PITELLI, R. A. Interferência de plantas daninhas em culturas agrícolas. Inf. Agropec., v. 11, p. 16-27, 1985.

Planta Daninha, Viçosa-MG, v.20, n.2, p.189-196, 2002 
RADOSEVICH, S. R.; HOLT, J. S. Weed ecology:

inplications for management. New York: John Wiley \& Sons, 1984. p. 93-193.

REJMANEK, M.; ROBINSON, G. R.; REJMANKOVA, E. Associated growth of wheat and annual ryegrass. I. Effect of varying total density and proportion in mixtures of wheat and annual ryegrass. Austr. J. Agric. Res., v. 31, p. 649$658,1989$.

RODRIGUES, B. N. Estudos sobre a dormência, crescimento, absorção de macronutrientes e resposta à calagem por Commelina benghalensis L.. Jaboticabal: FCAV/UNESP, 1992. 129 p. Tese (Doutorado em Produção Vegetal) - Universidade Estadual Paulista, 1992.

ROUSH, M. L.; RADOSEVICH, S. R. Relationships between growth and competitiveness of four annual weeds. J. Appl. Ecol., v. 22, p. 895-905, 1985.
SARRUGE, J. R.; HAAG, H. P. Análises químicas em plantas. Piracicaba: ESALQ/USP, 1974. 56 p. Não publicado.

SILVA, M. R. M.; MARENCO, R. A. Crescimento de Ischaemum rugosum sob três níveis de sombreamento. Planta Daninha, v. 18, n. 2, p. 187-198, 2000.

TANJI, A.; ZIMDAHL, R. L.; WESTRA, P. Competitive ability of wheat (Triticum aestivum) compared to rigid ryegrass (Lolium rigidum) and cowcockle (Vaccaria hispanica). Weed Sci., v. 45, p. 481-487, 1997.

VELINI, E. D. Avaliação dos efeitos de comunidades infestante naturais, controladas por diferentes períodos, sobre o crescimento e produtividade da cultura da soja [Glycine max (l.) Merril]. Jaboticabal: FCAV/UNESP, 1989. 152 p. Dissertação (Mestrado em Produção Vegetal) - Universidade Estadual Paulista, Jaboticabel, 1989. 